\title{
Mapeando master classes em instrumento musical: um olhar quantitativo sobre as relações entre professor, aluno e performance nesse formato de ensino
}

\author{
Ricieri Carlini Zorzal (Universidade Federal do Maranhão, São Luís, Brasil) \\ ricieri@pq.cnpq.br \\ Daniela da Costa Coimbra (Porto Polytechnic Institute, Porto, Portugal) \\ danielacoimbra@esmae.ipp.pt
}

\begin{abstract}
Resumo: Este artigo objetiva mapear as relações de tempo estabelecidas entre professor, aluno e suas respectivas performances em um contexto de master class. Para tanto, o conceito de master class é inicialmente discutido e um breve panorama de pesquisas na área é apresentado. Em termos metodológicos, adota-se uma amostra de 130 master classes de violão, gravadas em festivais de música sediados no Brasil e em Portugal. Essas master classes são analisadas conforme os seguintes parâmetros: 1) duração média; 2) relação entre a duração da obra executada pelo aluno e a duração da master class; 3) relação entre fala do professor, fala do aluno, performance do professor e performance do aluno; e 4) o momento em que a obra executada pelo aluno ocorre em uma master class. Os resultados indicam que: 1) a duração média de uma master class é de pouco mais de meia hora, mas é passível de grande variabilidade; 2) a duração da obra executada pelo aluno exerce apenas moderada influência na duração final de uma master class; 3) as master classes são dominadas pela fala do professor e pela performance do aluno; e 4) há um recorrente, porém curto, intervalo de tempo que precede a performance do aluno, e parece haver indícios que esse momento é de extrema importância para a efetividade da aula. Por fim, esses resultados são discutidos em termos de futuras pesquisas de cunho qualitativo.
\end{abstract}

Palavras-chave: Master class; Ensino de instrumento musical; Análise quantitativa; Alocação de tempo em ambientes de ensino.

\section{Mapping musical instrument master classes: A quantitative survey on teacher-student- performance relationship within this teaching format}

\begin{abstract}
This paper aims to map the time relation established between teacher, student, and their respective performances within a master class context. Therefore, a master class concept is initially discussed and a brief overview of the research on this subject is presented. In methodological terms, it is adopted a 130 guitar master class sample, which was video recorded in pedagogical music events held in Brazil and Portugal. Those master classes are analyzed according to the upcoming parameters: 1) Average master class time duration; 2) the relation between the time duration of the musical piece performed by the student and the time duration of the master class; 3 ) the relation between teacher's speaking time, student's speaking time, teacher's performance, and student's performance; and 4) the moment when the student performs. The results indicate that: 1) The average master class time duration is a bit over thirty minutes, but it is subject to great variability; 2) the time duration of the musical work performed by the student exerts only moderate influence on the master class time duration; 3) the master classes are dominated by the teacher's verbal strategies and the student's performance; and 4) there is a recurrent but short period of time preceding the student's performance and that there seem to be indications that this moment is of extreme importance for the lesson effectiveness. Ultimately, these results are discussed in terms of future qualitative research.
\end{abstract}

Keywords: Master class; Musical instrument teaching; Quantitative analysis; Allocation time in teaching settings.

\section{Introdução}

A master class é um formato de ensino que tem despertado um crescente interesse na pesquisa em Educação Musical. Em grande medida, tal interesse deve-se ao fato de que esse formato possui uma versatilidade de aplicação que o torna apropriado para situações de ensino em praticamente todas as etapas do desenvolvimento musical. A professora Cristina 
Tourinho, por exemplo, que possui extensa carreira no ensino coletivo de violão, defende que a disposição física dos alunos sugerida pela master class pode ser interessante desde os primeiros passos no instrumento, pois as informações dadas pelo professor ao aluno executante podem ser aproveitadas também por aqueles alunos que não estão tocando:

Sentam lado a lado o professor e um estudante, e os demais acompanham com a partitura, sentados em frente da dupla em linha única. As explicações dadas pelo professor ao estudante que está tocando devem ser dirigidas a todos e que também devem ser estimulados a oferecer sugestões para a solução dos problemas encontrados (dedilhados, fraseados, dinâmica, concepção musical). O professor deve propor a escuta consciente e a tomada de decisões musicais, que podem acontecer desde o repertório mais simples de um aluno iniciante (TOURINHO, 2006).

Na mesma linha de Tourinho (2006), o educador musical Keith Swanwick propõe a master class como um formato de ensino efetivo, quando um grupo engajado assume um compromisso educacional durante toda a aula:

Os requisitos básicos para qualquer pessoa tocar um instrumento são: o escutar cuidadoso e a observação perceptiva. Um grupo com um bom professor proporciona o ambiente ideal para o desenvolvimento dessas atitudes. Podemos pensar em master classes para qualquer faixa etária ou nível, onde cada um possa aprender alguma coisa. Prestar atenção no som de outra pessoa, na sua postura e estilo de performance, seu desenvolvimento técnico; tudo isto é parte da motivação que um grupo pode fornecer. Inclua-se aí também o estímulo dos triunfos dos colegas e o reconhecimento de suas dificuldades. Além disto, existe a possibilidade da aprendizagem por "osmose", por observação indireta, por apenas "estar ali presente" (SWANWICK, 1994, p. 8-9).

Além de sua eficácia nas etapas iniciais do desenvolvimento musical, a master class também pode ser extremamente útil com estudantes em nível avançado. Em suas discussões sobre as demandas da prática profissional e sobre como esse formato de ensino pode contribuir para a formação de futuros experts, Donald Schon (2000) discorre sobre três casos em que reconhecidos performers desenvolvem estratégias objetivamente direcionadas para os problemas que lhes são apresentados pelos alunos nesse tipo de contexto ${ }^{1}$. Essa capacidade de pensar em soluções inéditas para problemas reais, vista em ambientes profissionais criativos como ainda mais interessante que o know-what e o know-how, é o que o autor chama de reflexão na ação e é o que vai definir um profissional de excelência ${ }^{2}$. Ou seja, Schon (2000)_aponta a master class como uma experiência real na qual se pode pensar uma solução adequada para um problema em contexto. Consequentemente, o conhecimento gerado nessa situação problema-solução pode ser ampliado para outros contextos. Por esse motivo, a experiência da master class também deve fazer parte da vida de estudantes nos níveis mais adiantados do desenvolvimento musical. Assim, Schon comenta que:

Em uma master class em execução musical, um instrutor trabalha com um estudante avançado que preparou uma peça do repertório de seu instrumento. O professor tenta transmitir algo a respeito da compreensão e da comunicação da peça em questão, mas poderá também transmitir concepções aplicáveis à execução de outras peças, na verdade, à execução em geral. (SCHON, 2000, p. 173).

Em consonância com as ideias de Schon (2000), as pesquisas em educação musical têm visto a master class como um formato de ensino intimamente associado aos níveis mais elevados de performance musical. Dessa forma, muitos conservatórios e cursos superiores de música têm oferecido master classes como um complemento ao ensino tutorial regular e muitas universidades têm pautado suas discussões acadêmicas sobre os prós e contras 
desse formato (HANKEN, 2010). Por exemplo, a Academia Norueguesa de Música sediou, em dezembro de 2011, um simpósio internacional do qual resultou um documento que fornece orientações e diretrizes bastante pertinentes sobre todos os agentes envolvidos em uma master class (professor, estudante, o papel da plateia, o papel dos pesquisadores, organizadores, etc. [HANKEN; LONG, 2012]).

Dado o simpósio sediado pela Academia Norueguesa de Música, o Guildhall School of Music and Drama, instituição inglesa que abriga ativos pesquisadores da área, paralelamente, conduziu um projeto de pesquisa cujo principal objetivo foi construir um mapa delineando o desenvolvimento de habilidades musicais específicas e de pensamentos criativos transferíveis que são observados em master classes (para um relatório desse projeto, ver Long et al., 2011). Esse projeto resultou em uma série de publicações que ofereceram um suporte teórico mais robusto para o conceito de master class e contribuíram para um melhor entendimento sobre como os estudantes percebem e experimentam esse formato de ensino (LONG et al., 2014; LONG et al., 2012a; LONG et al., 2012b).

Nessa profícua discussão, a master class tem sido definida nos seguintes termos:

Uma master class é uma forma particular de ensino e aprendizagem na qual ocorre um encontro único entre um aluno e um eminente professor em frente a uma audiência. A configuração da master class coloca o aluno sob considerável pressão para criar uma favorável impressão, e o impacto imediato do contexto e a nova perspectiva de um professor expert podem atuar como um catalisador para a mudança, acelerando o trabalho que já está em andamento nas aulas regulares do aluno (LONG, 2013, p. $135)^{3}$.

Além disso, a master class tem sido descrita em quatro diferentes formatos (CREECH et al., 2009) e em três estilos gerais de organização (LONG et al, 2011). Creech e colegas apontam que uma master class pode ser: pública; específica do instrumento; estilística; ou aula de performance. Como destacam esses autores:

O termo genérico 'master class' é usado de forma diversificada para descrever eventos públicos onde artistas treinam estudantes avançados ou jovens profissionais, master class em menor escala com performers profissionais e específica para o instrumento, master classes estilísticas conduzidas por experts em um estilo ou gênero musical particular e, finalmente, aulas mais intimistas de performance dadas por professores de instrumento ou de voz para seus próprios estudantes (ou para outros estudantes de sua faculdade) (CREECH et al., 2009, p. 315) ${ }^{4}$.

Em termos de estilos gerais nos quais as master classes são organizadas, Long e colegas apontam os seguintes modelos: 1) tradicional (modelo predominantemente concordante com as definições apresentadas acima); 2) variações sobre o modelo tradicional (por exemplo, uma master class ministrada por um performer internacionalmente renomado, mas sem a presença de uma plateia); e 3) modelos não tradicionais (por exemplo, uma master class envolvendo dois professores em uma situação de coensino) (LONG et al., 2011) .

Pelo exposto, percebe-se o quão importante é a continuidade dos estudos sobre a master class nos seus diferentes formatos e variados estilos de organização em todos os níveis de desenvolvimento musical. Nesse sentido, o presente estudo levanta questões que têm sido caras tanto aos estudantes de música, quanto aos professores de instrumento musical. Por exemplo, é possível estabelecer o tempo médio de duração de uma master class? Uma resposta a essa questão teria um impacto direto na organização e no desenvolvimento da aula. Outra questão que se pode colocar é: a obra tocada pelo aluno exerce alguma 
influência na duração final de uma master class? Uma avaliação sobre essa possível relação pode ajudar o estudante de instrumento a escolher o repertório a ser tocado. Além disso, de que forma o tempo total de uma master class é distribuído entre professor, aluno e suas respectivas performances? A identificação dessas relações pode fomentar o comportamento crítico dos envolvidos nesse ambiente de ensino. Assim, entende-se que a Educação Musical, ao compreender as microrrelações de tempo estabelecidas em master classes, pode contribuir com estratégias que otimizem o complexo processo de ensino-aprendizagem que ocorre nesse formato de ensino.

Em consonância com as questões acima, este artigo tenciona lançar um olhar quantitativo sobre determinados eventos que ocorrem em master classes, com a finalidade de descrever mais efetivamente aspectos estruturais desse processo de ensino (KARLSSON, JUSLIN, 2008). Dessa forma, objetiva-se mapear as relações de tempo estabelecidas entre professor, aluno e performances em uma significativa amostra de master classes para, com o devido suporte estatístico, identificar padrões de comportamento e orientar futuras pesquisas de caráter qualitativo.

\section{Metodologia}

A amostra deste estudo foi composta de 130 master classes gravadas em seis diferentes festivais de violão: dois deles sediados em Portugal e os outros quatro sediados no Brasil. As master classes dessa amostra envolveram exclusivamente o ensino do violão, portanto todo o repertório musical apresentado estava relacionado ao instrumento. Como consequência dessa abordagem, as master classes aqui analisadas foram do modelo tradicional e voltadas para um instrumento específico (LONG et al., 2011). As gravações foram realizadas segundo as normas da observação não participativa, com gravação em áudio e vídeo estabelecidas pela literatura (DANIEL, 2006). A Tabela 1 apresenta as características dessa amostra:

Tabela 1 - Informações gerais sobre a amostra de 130 master classes

\begin{tabular}{|l|l|r|r|r|}
\hline \multirow{2}{*}{$\begin{array}{c}\text { País de realização } \\
\text { da master class }\end{array}$} & $\begin{array}{l}\text { Forma de obtenção } \\
\text { do material }\end{array}$ & $\begin{array}{l}\text { Número de } \\
\text { professores } \\
\text { envolvidos }\end{array}$ & $\begin{array}{c}\text { Número de alunos } \\
\text { envolvidos }\end{array}$ & $\begin{array}{c}\text { Número de master } \\
\text { classes realizadas }\end{array}$ \\
\hline \multirow{3}{*}{ Portugal } & Acervo de terceiros & 9 & 58 & 82 \\
\cline { 2 - 6 } & $\begin{array}{l}\text { Gravado in loco } \\
\text { pelos pesquisadores }\end{array}$ & 2 & 8 & 10 \\
\hline \multirow{3}{*}{ Brasil } & Acervo de terceiros & 6 & 26 & 30 \\
\cline { 2 - 6 } & $\begin{array}{l}\text { Gravado in loco } \\
\text { pelos pesquisadores }\end{array}$ & 18 & 100 & 130 \\
\hline
\end{tabular}

Fonte: Elaboração própria.

A partir dessa amostra, métodos quantitativos descritivos, análises de tendência central e regressões lineares descreveram as relações gerais estabelecidas em termos de duração, proporcionalidade e média dos eventos estudados. Assim, foram investigadas diferentes questões, tais como: a duração de uma master class; a relação entre a duração da obra executada pelo aluno e a duração da master class; a relação de proporcionalidade entre a fala do professor, a fala do aluno, a performance do professor e a performance do aluno (ou seja, a fração que cada uma dessas variáveis representa em termos da duração total de uma master class); e o momento em que a obra executada pelo aluno ocorre em 
uma master class. Dessa forma, essa descrição procurou especificar as propriedades, as características e os perfis dos fenômenos submetidos à análise (SAMPIERI et al., 2006), o que reforça seu caráter exploratório. Como sumariza Beran:

O objetivo primário da estatística descritiva é sumarizar dados por meio de um pequeno arranjo de números ou apresentações gráficas com o propósito de encontrar aspectos relevantes típicos. Uma análise descritiva em profundidade explora os dados ao maior grau possível na esperança de encontrar alguma coisa interessante. Essa atividade é também chamada "análise exploratória de dados" ou "exploração de dados". A análise exploratória de dados não exige um modelo de hipótese anterior, o propósito é simplesmente a exploração livre ${ }^{6}(2004$, p. 27).

Mais especificamente, a duração média das master classes foi analisada a partir da curva normal e dos parâmetros de sua distribuição, ou seja, média e desvio padrão; a relação entre a duração da obra executada pelo aluno e a duração da master class foi estipulada através de uma regressão linear; e os demais eventos foram analisados por meio de razões matemáticas simples. Essas informações foram plotadas no SPSS e no Excel.

\section{Análise e discussão dos dados:}

\subsection{A duração de uma master class}

Embora alguns organizadores de eventos que promovem master classes deem alguma orientação sobre o tempo que o professor deve dedicar a cada aluno, orientação que costuma ser de trinta minutos, percebe-se que a duração de uma master class ainda não é nem bem regulamentada, como os cinquenta minutos de uma aula em uma instituição escolar, nem tradicionalmente estabelecida, como o tempo de uma hora que geralmente têm as aulas particulares de instrumento musical. Não surpreendentemente, essa falta de regulamentação ou tradição refletiu-se naquela amostra. Os dados aqui analisados variaram de pouco menos de onze minutos para a master class mais curta, até uma hora e meia para a mais longa.

A Figura 1 apresenta um gráfico da frequência de ocorrência por intervalo de duração das cento e trinta master classes pesquisadas. Como pode ser visto no gráfico abaixo, essa amostra resultou em uma duração média de pouco mais de meia hora, porém houve uma grande variabilidade desse valor $(\mathrm{N}=130 ; \mathrm{M}=00: 34: 37 \text {; } \mathrm{SD}=00: 26: 46)^{7}$. 
Figura 1 - Representação da curva normal da frequência de ocorrência por intervalo de duração das 130 master classes

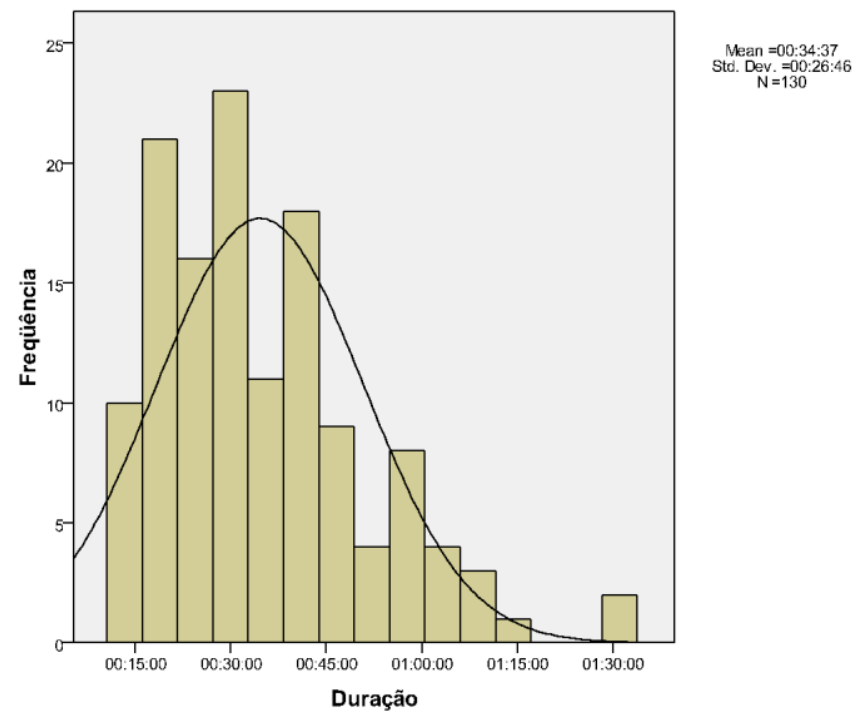

Fonte: Elaboração própria.

O intervalo de confiança estipulado para o cálculo da média foi de 95\%. Os limites inferior e superior desse intervalo são, respectivamente, 00:31:48 e 00:37:26. Isso significa que, estatisticamente, há noventa e cinco por cento de certeza que esse intervalo englobe a duração média real de todas as master classes. Nota-se nessa amostra, todavia, que a maior parte das master classes apresenta durações superiores a vinte minutos e inferiores a quarenta e cinco minutos. Essa concentração, não compensada pela baixa frequência de master classes com duração superior a uma hora, faz emergir uma assimetria positiva para a curva normal. Percebe-se, inclusive, alguns intervalos de duração com frequência igual a zero.

Uma representação da curva normal que apresenta uma assimetria significa dizer que os valores da média e da mediana dos dados que geraram essa curva são diferentes. Enquanto a média retorna à média aritmética dos dados coletados, a mediana é um valor que divide o conjunto de dados coletados exatamente ao meio. Nesse caso, têm-se sessenta e cinco master classes com duração inferior ao valor da mediana e sessenta e cinco master classes com duração superior. A mediana apresenta uma vantagem analítica em relação à média, pois não é tão sensível a dados com valores que divergem demasiadamente da tendência central. Por exemplo, na Figura 1, vista acima, parece que algumas durações, como as master classes em torno de uma hora e meia, destoam da maioria dos dados.

O boxplot, ou diagrama de caixa, é uma forma gráfica conveniente de apresentar uma tendência central dos dados através da mediana. O retângulo do boxplot representa $50 \%$ dos valores centrais da distribuição dos dados. A linha que corta o retângulo é a mediana. As linhas horizontais abaixo e acima do retângulo apresentam, respectivamente, o menor e o maior valor observado, desde que esses valores não superem uma razão dos valores de tendência central. Os pontos abaixo ou acima desse limite são chamados outliẹ:s, ou_observações atípicas.

Essa amostra apresenta 50\% das master classes com duração entre 00:23:42 e 00:43:13. O valor da mediana é de 00:30:29. A menor e maior duração observada foram de, respectivamente, 00:10:31 e 01:11:19. Três casos foram considerados atípicos. A Figura 2 apresenta graficamente os valores discutidos. 
Figura 2 - Gráfico de tendência central da duração das 130 master classes

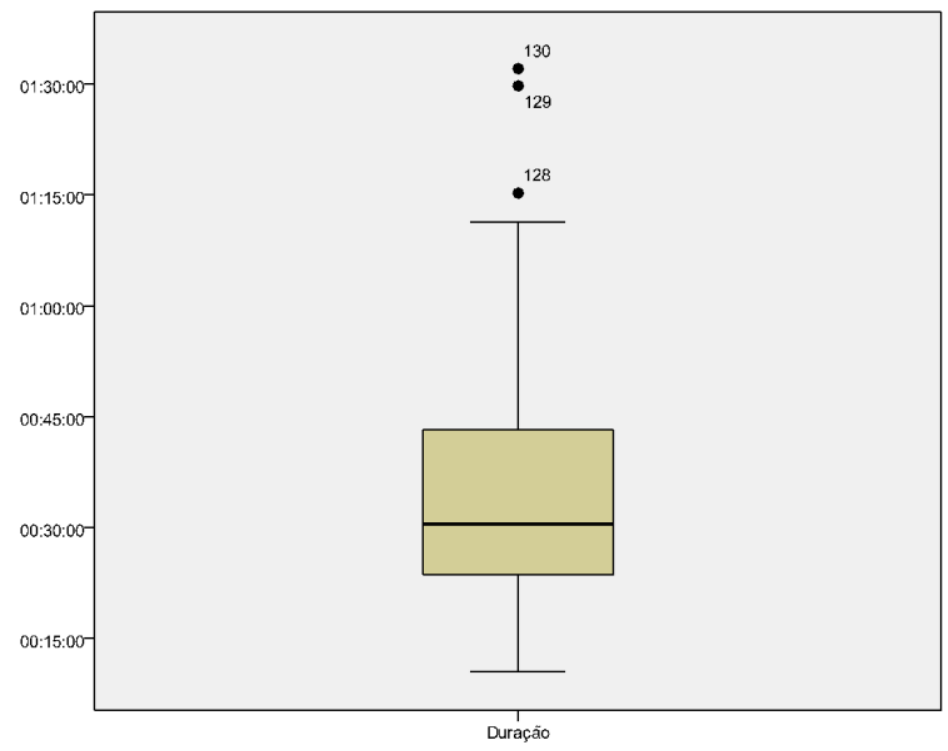

Fonte: Elaboração própria.

Portanto, após a análise da média e da mediana, indica-se que as master classes tenham durações que giram em torno de trinta minutos. Contudo, tal resultado deve ser visto com parcimônia, pois o grande desvio padrão apresentado pelos dados coletados (SD = 00:26:46) mostra que essa duração pode ser bem diferente.

Pelo exposto, sugere-se que a prática de orientar o professor sobre o tempo que ele deve dedicar a cada aluno em master classes, prática essa adotada por alguns organizadores de eventos, tem algum efeito na média geral da duração das master classes. Todavia, quando não se tem essa orientação, a duração de uma master class parece ser o resultado de um complexo conjunto de fatores que torna difícil sua previsibilidade. Entre esses fatores podem estar: características individuais da prática de ensino do professor; o nível de performance em que se encontra o aluno; o grau de dificuldade da obra executada; ou até mesmo a duração da obra executada pelo aluno. Discute-se, a seguir, um pouco mais sobre o último caso.

\subsection{A duração da obra executada pelo aluno}

Ao se pensar na duração de uma master class, parece razoável supor que a duração da obra executada pelo aluno nessa master class exerça algum tipo de influência. Essa suposição segue a seguinte lógica: quanto mais tempo o aluno toca para o professor, mais detalhes o professor pode ter para falar para o aluno e, consequentemente, mais longa pode ser a aula. Para investigar essa possível influência, propõe-se aqui um modelo de análise com o objetivo de determinar o grau de dependência entre a duração da obra executada pelo aluno, assumida ser a variável independente, e a duração total da master class, assumida ser a variável dependente desse modelo. Todavia, antes de se iniciar a análise propriamente dita, é preciso esclarecer algumas particularidades das observações realizadas.

Primeiramente, houve algumas interrupções do professor durante a performance do aluno em algumas das master classes observadas. Isso aconteceu, principalmente, quando havia na obra seções musicais que eram idênticas ou muito semelhantes a seções anteriores. Um exemplo disso ocorreu com um aluno que tocou o primeiro movimento da Sonata em $C$, de Mauro Giuliani. Assim que esse aluno terminou o desenvolvimento dessa Sonata, o professor o interrompeu e começou a dar suas dicas de performance. O mesmo 
aconteceu com um aluno que tocou o primeiro movimento da Sonata III, do compositor mexicano Manuel Maria Ponce. A segunda particularidade diz respeito a obras do tipo tema com variações. Ocorreu, às vezes, de o aluno tocar as variações intercaladas por dicas de performance do professor. Esse foi o caso das master classes sobre o Nocturnal, de Benjamin Britten, e sobre o Theme and Variations, de Lennox Berkeley. Dito isso, percebe-se que a duração da obra exe

cutada pelo aluno nem sempre é a duração real média da obra e que essa execução nem sempre é ininterrupta. Nesses casos, adotou-se o procedimento de somar os momentos da performance do aluno até que o professor considerasse a obra executada em sua totalidade.

A Figura 3 apresenta as relações entre as durações da obra executada pelo aluno e da master class em que essa obra foi executada. Os dados mostram que, embora a força da relação seja apenas moderada $\left(\mathrm{r}^{2}=0,693\right)$, vista a grande dispersão dos dados, parece haver uma certa dependência entre as variáveis em um modelo de regressão linear. Ou seja, a duração da obra executada pelo aluno pode exercer uma moderada influência na duração final da master class.

Figura 3 - Relação entre a duração da obra executada pelo aluno e a duração final da master class

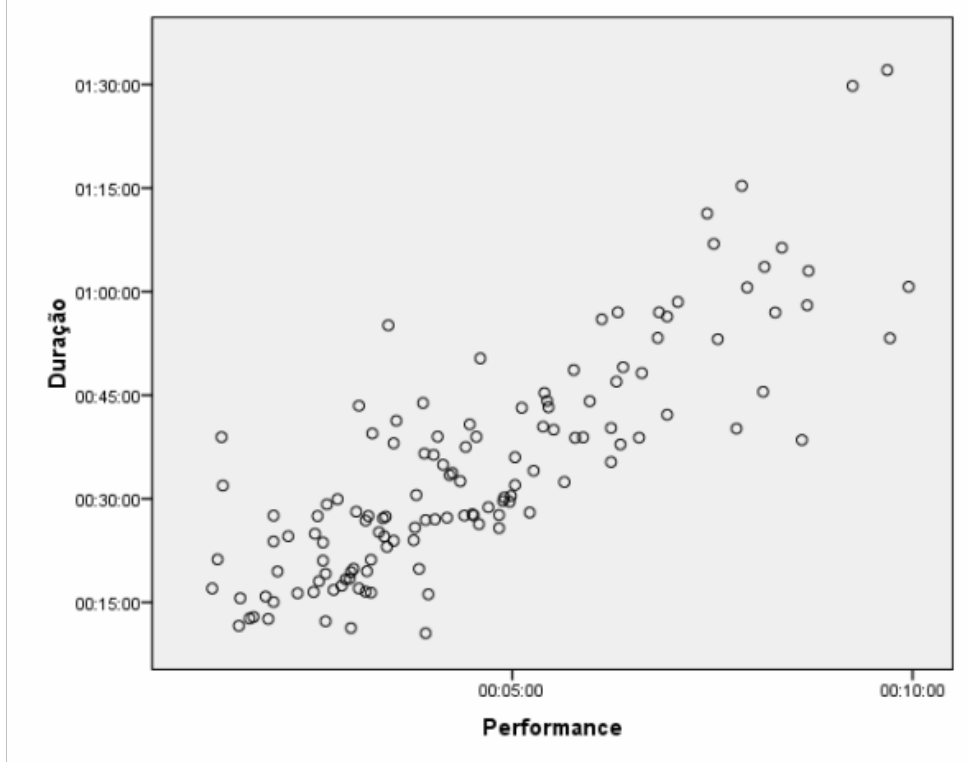

Fonte: Elaboração própria.

Os resultados discutidos acima reforçam a ideia de que a duração final de uma master class é o resultado de uma complexa interação de diferentes fatores. Contudo, parece haver algum fundamento para supor que, se o aluno opta por uma obra de grande porte ou executa seu repertório um pouco mais lentamente, ele tem alguma chance de passar um tempo um pouco maior com o professor.

\subsection{0 momento de início da performance do aluno}

Como visto acima, outra particularidade da master class é o fato de que, geralmente, professor e aluno não mantêm um contato pedagógico regular (ZORZAL;_LORENZO, 2017), o que indica que o professor pode não ter muitas informações prévias sobre o desenvolvimento musical do aluno. Portanto, por um lado, parece razoável supor que o professor precise, bem no início da aula, de elementos que indiquem o nível de performance do aluno com 
precisão, com o objetivo de empregar as estratégias de ensino necessárias. Isso sugere que a obra que o aluno tenciona executar seja apresentada já no começo da aula.

Por outro lado, a master class, sob a ótica dos alunos, pode estar envolta em uma atmosfera hostil e intimidadora (LONG et al., 2014). E, como mostra a literatura científica, tal constatação tem o poder de despertar uma série de emoções negativas que podem comprometer a performance final do aluno e, consequentemente, distorcer a avaliação do professor $^{8}$. Portanto, parece haver uma necessidade de o aluno dispor de algum tempo para tentar controlar essa ebulição de emoções negativas antes de iniciar sua performance. Pelas razões acima expostas, este tópico avaliará o tempo médio que o aluno levará para iniciar sua performance em uma situação de master class.

Para esta investigação, foi medido o tempo decorrido desde o início da master class, ou seja, o instante em que o aluno se senta, até o momento em que o aluno começa sua performance. Após isso, foi calculada a fração de tempo que esse intervalo representou em relação à duração total da master class para, então, ser calculada uma média dos percentuais obtidos. Os resultados mostram que, em média, o aluno inicia sua performance antes de decorridos $5 \%$ da duração total da master class. Isso significa dizer que, se uma master class dura trinta minutos, a performance do aluno é iniciada, em média, antes de decorridos um minuto e meio da aula.

Os resultados obtidos reforçam a ideia de que a obra executada pelo aluno é fonte imprescindível, e praticamente única, de informações para orientar o trabalho do professor nesse formato de ensino. Contudo, embora pareça não haver um aprofundado diálogo anterior a essa performance, há um pequeno intervalo de tempo que pode ser de extrema utilidade para uma maior efetividade da aula. A partir dessa constatação, emergem questões que têm sido negligenciadas pela Educação Musical: o que acontece nos primeiros instantes desse contato_entre professor e aluno, que pode ser único, em uma situação de master class? Como o aluno enfrenta esse ambiente que pode ser visto como hostil? Como o professor lida com as primeiras reações do aluno?

Talvez esse tópico tenha trazido mais perguntas do que respostas, porém ficam indicações para pesquisas futuras. Uma abordagem de caráter mais qualitativo pode sugerir caminhos para um melhor aproveitamento das estratégias nesse formato de ensino.

\subsection{A divisão do tempo entre professor e aluno em master classes}

Como professor e aluno utilizam o tempo de uma master class, isso se torna uma questão de extrema importância para um maior entendimento desse formato de ensino. Para analisar essa questão, a duração das master classes foram divididas em quatro unidades de análise. Portanto, foram medidos: 1) o tempo gasto com a fala do aluno; 2) o tempo gasto com a performance do aluno; 3) o tempo gasto com a fala do professor; e 4) o tempo gasto com a performance do professor. Esses tempos foram calculados em termos proporcionais em relação à duração das master classes e apresentados em termos de média simples. Essas informações são mostradas na figura abaixo. 
Figura 4 - percentuais médios do tempo gasto entre professor e aluno em master class

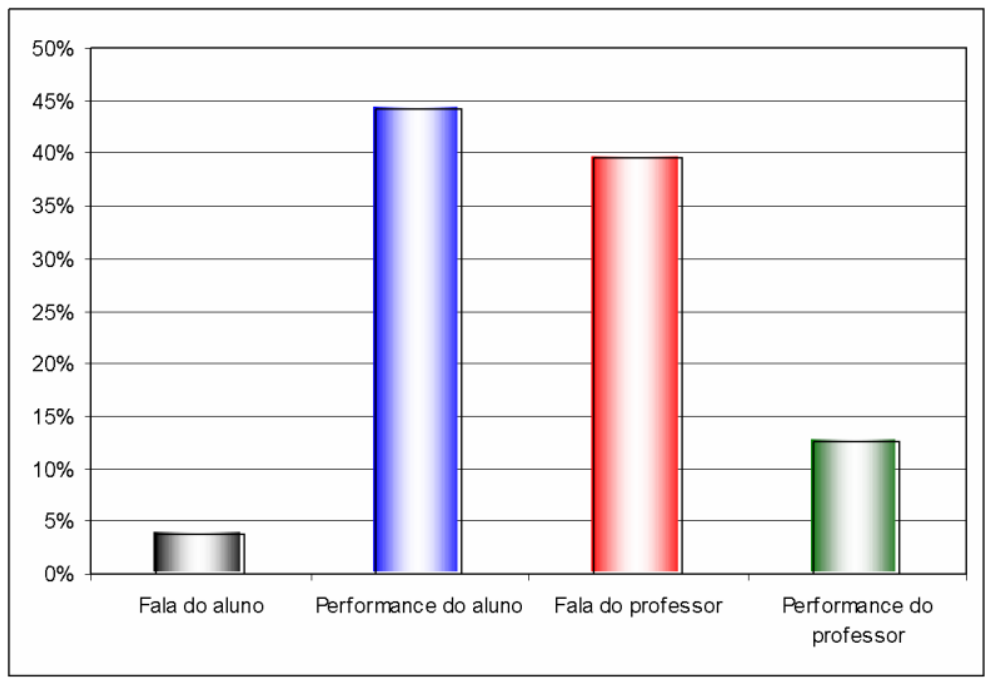

Fonte: Elaboração própria.

A Figura 4 indica que professor e aluno dividem quase equanimemente o tempo total. Os dados mostram que, somando o tempo gasto com a fala e com a performance, o professor tomou, em média, 52,1\% do tempo da master class. O aluno, por sua vez, tomou $47,9 \%$ do tempo da aula entre fala e performance. Essa diferença não foi estatisticamente significativa $(p<0,01)$. O ponto a ser observado corresponde ao momento em que o professor e o aluno aplicam o tempo durante a master class.

Um olhar mais próximo sugere que uma master class é dominada pela performance do aluno e pela fala do professor. Nesse sentido, pode-se dizer que há indícios de que a aula é orientada pela fala do professor, seguida pela resposta musical do aluno.

A fala do aluno representou, em quase todas as master classes, uma fração de tempo significativamente inferior da aula, uma média de 3,7\% da duração total (durante as observações percebeu-se que, na maior parte desse tempo, o aluno limitava-se a responder perguntas pontuais feitas pelos professores. Todavia, essas observações são preliminares e precisam de escrutínio científico). Assim, o aluno, quando de posse do tempo, colocavase predominantemente por meio de sua performance $(44,2 \%)$. Já o professor, embora passasse boa parte de seu tempo empregando estratégias verbais de ensino, uma média de $39,5 \%$ do tempo total, fez considerável uso da demonstração instrumental $(12,6 \%)^{9}$. Essa complementariedade entre estratégias verbais e demonstração instrumental está bem fundamentada na literatura (ALTENMÜLLER, GRUHN, 2002; WOODY, 2002, 2004, 2006; ZORZAL, 2007).

A discussão acima mostra que a master class é um formato de ensino de instrumento musical que privilegia pouco o diálogo verbal entre os envolvidos. A questão que permanece, e que precisa ser estudada de forma aprofundada, é se o aluno consegue expressar-se musicalmente somente por meio de sua performance ou se ele apenas reproduz ideias interpretativas sugeridas pelo professor.

\section{Apontamentos finais e direções futuras}

O presente estudo teve como objetivo mapear as relações de tempo estabelecidas em uma amostra de 130 master classes, e os primeiros dados analisados levantaram informações sobre o tempo médio que dura uma aula nesse formato de ensino. Esses dados indicaram que a master class é influenciada por uma complexa interação de fatores que torna difícil 
realizar alguma previsão de sua duração final. Todavia, dois aspectos emergiram nesse sentido.

Primeiramente, apesar de uma enorme variabilidade, a duração média das master classes aqui analisadas girou em torno de meia hora, o que representa uma orientação de tempo comumente feita pelos organizadores de eventos pedagógicos musicais que promovem esse formato de ensino. Portanto, passa a ser necessário investigar os possíveis ganhos e prejuízos de se estabelecer, a priori, um tempo máximo para uma aula cujo conteúdo a ser trabalhado pelo professor não passa por nenhum planejamento prévio.

Em segundo lugar, parece que a duração da obra executada pelo aluno pode exercer uma leve influência na duração final da master class. Dessa forma, alunos que desejam passar um tempo um pouco maior com o professor podem decidir tocar mais lentamente seu repertório ou escolher tocar obras de grande porte, embora sejam aquelas que contenham repetições estruturais (como aquelas que seguem a forma sonata), ou aquelas compostas como pequenas sequências (como os temas com variações), que tendem a ser interrompidas pelo professor.

Uma análise adicional dos dados mostrou que os momentos que precedem o início da performance do aluno em uma master class merecem maior atenção por parte dos pesquisadores em Educação Musical. A literatura tem mostrado que a master class tende a ser um evento importante no sentido de que ela se configura como uma oportunidade de encontro entre um performer, que geralmente goza de muito prestígio na área (LONG et al., 2012a; 2012b), com um estudante que está dando os primeiros passos nessa comunidade de prática profissional e cujos conceitos de prática musical e planejamento da performance ainda estão em formação (ZORZAL, 2015). Contudo, esse encontro pode ser visto como amedrontador pelo aluno (LONG et al., 2014).

Assim, este artigo evidenciou que um tempo médio relativamente curto precede a performance do aluno, mas que esse tempo pode ser otimizado. Por exemplo, pode-se pensar em técnicas específicas de relaxamento e concentração para que o aluno enfrente eficientemente esses momentos de tensão e, concomitantemente, pode-se pensar em estratégias para que os professores proporcionem aos alunos um ambiente de aprendizagem que diminua a incidência de fatores que possam comprometer uma precisa avaliação diagnóstica.

Ao longo do trabalho, por fim, os resultados reforçaram que a master class é dominada pela performance doaluno e pela fala do professor. Essa constataçãotem encontrado ressonância na literatura (DANIEL, 2006; KARLSSON, JUSLIN, 2008), como também indica que o aluno, majoritariamente, responde tocando as orientações verbais do professor. Em outras palavras, parece não haver diálogos, discussões ou debates críticos acerca das orientações recebidas. Por promover um papel dominante para o professor, esse modelo mestre-aprendiz de ensino e aprendizagem tem sido alvo de fortes críticas (LONG, 2013).

Uma ideia para mudar essa realidade pode ser sugerir que os alunos, em vez de apenas tentarem reproduzir as instruções do professor, sejam mais estimulados tanto a questionar os porquês de certas opções estilístico-interpretativas, quanto a argumentar sobre algumas instruções técnico-musicais. Certamente, o questionamento e a argumentação devem ser nutridos com fundamentos sólidos, e é exatamente aí que está o importante papel do professor-tutor nesse contexto. Ao saber que seu aluno vai enfrentar uma master class com um reconhecido performer, o professor-tutor deve oferecer a esse aluno uma estrutura teórico- conceitual com a qual ele poderá trabalhar aspectos mais aprofundados de seu repertório.

Uma vez que esse artigo trabalhou apenas com dados quantitativos, é mister destacar que as sugestões de cunho qualitativo dadas acima carecem de um maior suporte empírico. 
Embora esse trabalho qualitativo tenha sido iniciado por meio da realização de simpósios (HANKEN, LONG, 2012) e projetos de pesquisa (HADDON, 2014; LONG, 2013; LONG et al., 2011; ZORZAL; LORENZO, 2017) específicos sobre a master class e instrumento musical, ainda há um longo caminho a ser percorrido até um profundo entendimento desse complexo, desafiador e instigante formato de ensino.

\section{Notas}

1 Os três casos descritos por Schon (2000) são sobre uma aula ministrada para uma estudante de violino, sobre o caso em que um estudante recebe orientações do violoncelista Pablo Casals e sobre uma aula ministrada a um jovem talento do piano. Por sua capacidade de sempre fazer algo diferente, de especial interesse nessas descrições são as estratégias apresentadas por Casals.

2 Zorzal (2015) apresenta uma sólida estrutura teórica que mostra o papel da prática musical e do planejamento da performance nesse contexto de master class.

3 "A master class is a particular form of teaching and learning in which a one-off encounter between a student and an eminent master teacher takes place in the presence of an audience. The master class setting places the student under considerable pressure to make a favourable impression and the immediate impact of the setting and the fresh perspective of a master teacher may act as a catalyst for change, accelerating work that is already underway in the student's regular one-a-one lessons” (LONG, 2013, p. 135).

4 "The generic term 'master class' is used variously to describe public events where high-profile artists coach advanced students or young professionals, smaller-scale instrument-specific master classes with professional players, stylistic master classes led by experts in a particular musical style or genre and, finally, more intimate performance classes given by instrumental or vocal teachers for their own students (or for other students within their own faculty)" (CREECH et al., 2009, p. 315).

5 Outras definições de master class apresentadas pela literatura trazem conteúdos similares aos expostos acima. Para facilitar o trabalho de pesquisas futuras, tais definições são transcritas abaixo:

6 "[...] public master classes are high-profile occasions at which a master of international acclaim teaches students in the presence of a public audience. Conservatoires also organize master classes for their students and teachers with artists highly regarded for their expertise on their instrument, artists renowned for their specialized knowledge in a particular genre, period or style of music, or teachers within the conservatoire for their own students to develop performance skills and to provide a forum for peer appraisal" (LONG et al. 2012b, p. 684). "Public master classes showcase individual students in a public form of teaching and learning.” (LONG et al., 2012a, p. 287).

7 "[...] as classes given by a distinguished musician visiting the conservatoire intended for the benefit of staff and students of that instrument or related instruments.” (LONG et al., 2014, p. 178).

8 "Guitar master classes herein are defined as pedagogical events in the presence of an audience where experienced guitarists teach students the guitar and where the teacher and student do not maintain regular contact either before or after the class" (ZORZAL; LORENZO, 2017, p. 2).

9 "The primary aim of descriptive statistics is summarize data a small set of numbers or graphical displays, with the purpose of finding typical relevant features. An in-depth descriptive analysis explores the data as far as possible in the hope of finding anything interesting. This activity is therefore also called 'exploratory data analysis' (EDA) or 'data mining'. EDA does not require a priori model assumptions - the purpose is simply free exploration." (BERAN, 2004, p. 27).

10 Nomenclatura estatística adotada: tamanho da amostra (N); média (M); desvio padrão (SD). Todas as durações são apresentadas em horas, minutos e segundos.

11 Para uma revisão sobre ansiedade na performance, ver Kenny (2011).

12 Long e colegas (2011) apontam que esses percentuais podem variar conforme o modelo de master class adotado, o professor, o instrumento etc. Não obstante tal variação, a predominância da fala do professor e da performance do aluno parecem ser uma constante.

\section{Referências}

ALTENMÜLLER, Eckart; GRUHN, Wilfried. Brain Mechanisms. In: PARNCUTT, R.; MCPHERSON, G. E. (Ed.). The science and psychology of music performance: Creative strategies for teaching and learning. New York: Oxford University Press, 2002. p. 63-82.

BERAN, Jan. Interdisciplinary Statistics: Statistics in Musicology. London: Chapman \& Hall/ CRC, 2004. 
CREECH, Andrea; GAUNT, Helena; HALLAM, Susan; ROBERTSON, Linnhe. Conservatoire students' perceptions of master classes. British Journal of Music Education, v. 26, p. 315-331, 2009.

DANIEL, Ryan. Exploring music instrument teaching and learning environments: video analysis as a means of elucidating process and learning outcomes. Music Education Research, v. 8, n. 2, p. 191-215, 2006.

HADDON, Elizabeth. Observational learning in the music masterclass. British Journal of Music Education, v. 31, n. 1, p. 55-68, 2014.

HANKEN, Ingrid Maria. The benefits of the master class: The masters' perspective. Nordic Research in Music Education, Yearbook, v. 12, p. 149-160, 2010.

HANKEN, Ingrid Maria; LONG, Marion. Master classes - What do they offer? NMH-publikasjoner, v. 8, 2012. Disponível em: <http://hdl.handle.net/11250/172653>. Acesso em: 27 dez. 2017.

KARLSSON, Jessica; JUSLIN, Patrik. Musical expression: an observational study of instrumental teaching. Psychology of Music, v. 36, n. 3, p. 309-334, 2008.

KENNY, Dianna. The role of negative emotions in performance anxiety. In: JUSLIN, P.; SLOBODA, J. (Ed.), Handbook of music and emotion: Theory, research, applications. 2 ed. Oxford: UK, Oxford University Press, 2011. p. 425-452.

LONG, Marion. Exploring Cognitive Strategies and Collaboration in master class Settings. In: GAUNT, H.; WESTERLUND, H. (Ed.). Collaborative Learning in Higher Music Education. New York: Rotledge, 2013. p. 135-150.

LONG, Marion; CREECH, Andrea; GAUNT, Helena; HALLAM, Susam. Conservatoire students' experiences and perceptions of instrument specific master classes. Music Education Research, v. 16, p. 176-192, 2014.

LONG, Marion; CREECH, Andrea; GAUNT, Helena; HALLAM, Susam, ROBERTSON, Linnhe. Blast from the past: Conservatoire students' experiences and perceptions of public master classes. Musicae Scientiae, v. 16, p. 286-306, 2012a.

LONG, Marion; HALLAM, Susam; CREECH, Andrea; GAUNT, Helena; ROBERTSON, Linnhe. Do prior experience, gender, or level of study influence music students' perspectives on master classes? Psychology of Music, v. 40, p. 683-699, 2012b.

LONG, Marion; GAUNT, Helena; HALLAM, Susam; CREECH, Andrea. Mapping master classes: Format, content \& style. 2011. Disponível em: < https://www.academia.edu/2848688/Mapping Master_classes $>$. Acesso em: 18 nov. 2017.

SAMPIERI, Roberto Hernández; FERNÁNDEZ-COLLADO, Carlos; LUCIO, Pilar Batista. Metodología de la investigación. 4. ed. México: McGraw-Hill Interamericana, 2006. SCHON,

Donald. Educando o profissional reflexivo: um novo design para o ensino e aprendizagem. Porto Alegre: Artes Médicas Sul, 2000.

SWANWICK, Keith. Ensino instrumental enquanto ensino de música. In: KATER, C. (Ed.). Cadernos de Estudo: Educação Musical. São Paulo: Atravez, 1994. p. 7-13.

TOURINHO, Ana Cristina Gama dos Santos. Ensino coletivo de violão: proposta para disposição física de estudantes e atividades correlatas. In: KEHRWALD, M. I. P.; SILVEIRA, E. (Org.). Anais do $20^{\circ}$ Seminário Nacional de Arte e Educação. Montenegro: Editora da Fundarte, 2006. Disponível em: <http://artenaescola.org.br/sala-de- leitura/artigos/artigo.php?id=69356>. Acesso em: 23 nov. 2017. 
WOODY, Robert. Emotion, imagery and metaphor in the acquisition of musical performance skill. Music Education Research, v. 4, n. 2, p. 213-224, 2002.

WOODY, Robert. Musicians' cognitive translation of imagery into properties of expressive performance. Paper presented at the National Biennial Convention of MENC: The National Association for Music Education, Minneapolis, 2004.

. The Effect of Various Instructional Conditions on Expressive Music Performance. Journal of Research in Music Education, v. 54, n. 1, p. 21-36, 2006.

ZORZAL, Ricieri Carlini. Metáforas no ensino de música: um estudo de caso sobre o emprego de linguagem figurada em master-class de violão. In: SANTIAGO, D.; BORDINI, R. M. (Org.). Proceedings of the 3rd Symposium on Cognition and Musical Arts- International. Salvador: EDUFBA, 2007. p. 384-389.

. Prática musical e planejamento da performance: contribuições teórico-conceituais para o desenvolvimento da autonomia do estudante de instrumento musical. Opus, v. 21, n. 3, p. 83-110, dez. 2015.

ZORZAL, Ricieri; LORENZO, Oswaldo. Teacher-student physical contact as an approach for teaching guitar in the master class context. Psychology of Music, p. 1-14, 2017. DOI: 10.1177/0305735617737154.

$\overline{\text { Ricieri Carlini Zorzal é bacharel em Violão pela Universidade Federal de Minas Gerais, mestre em Práticas }}$ Interpretativas pela Universidade Federal da Bahia e doutor em Educação Musical pela Universidade Federal da Bahia. É Professor Associado I da Universidade Federal do Maranhão, onde exerceu, entre 2012 e 2015, a função de chefe do Departamento de Artes. Coordena o grupo ENSAIO (grupo de pesquisa em Ensino e Aprendizagem da Performance Musical), que tem projetos de pesquisa financiados pela FAPEMA e CNPq e tem publicado seus resultados em periódicos especializados e congressos no Brasil e no exterior.

Daniela da Costa Coimbra é professora adjunta e presidente do Conselho Técnico Científico na Escola Superior de Música e das Artes do Espectáculo do Porto. Doutorou-se em Psicologia da Música na Universidade de Sheffield, no Reino Unido, com uma bolsa da Fundação para a Ciência e Tecnologia. Ainda como bolseira da FCT realizou um pós-doutoramento no Centro de Investigação em Ciência e Tecnologia das Artes (CITAR) da Escola das Artes da Universidade Católica Portuguesa, no Porto, em colaboração com o Centre for Performance Science (CPS) do Royal College of Music em Londres. A sua investigação foca aspectos educacionais e psicológicos da prática musical. 